\title{
The Classification and Scientific Names of Rainbow and Cutthroat Trouts
}

\author{
Gerald R. Smith and Ralph F. Stearley
}

\begin{abstract}
Two unambiguous discoveries involving rainbow trout require scientific name changes. First, the rainbow trout has been demonstrated to be the same species as the Kamchatka trout. Second, studies of osteology and biochemistry of trout and salmon show that rainbow and cutthroat trout, and their close relatives, the golden, Mexican golden, Gila, and Apache trouts, are more closely related to Pacific salmons (Oncorhynchus) than to brown trout and Atlantic salmon (Salmo). The different names required by these two discoveries will cause some confusion in communications in which the formal classification is used, so we present evidence to acquaint biologists and managers with the rationale for the changes. The species name of the rainbow trout becomes mykiss, an older Latinized indigenous name of the Kamchatka trout. The generic designation of rainbow and cutthroat trout poses a more subjective problem, involving four possibilities: Salmo, Oncorhynchus, Rhabdofario, and Parasalmo. The balance of evidence indicates to us that the generic name for Pacific trouts and salmons should be Oncorhynchus. We suggest recognition of two divergent sister lineages, (1) Atlantic trout and salmon, and (2) Pacific trouts and salmons, as the genera Salmo and Oncorhynchus, respectively. Alternative generic classifications considered include the following: (a) Enlarge Salmo to include all Atlantic and Pacific trouts and salmons. This would be well supported by morphological and biochemical characters, but would fail to emphasize the distinctions between the Pacific and Atlantic groups. (b) Use a separate generic name, Rhabdofario, for rainbow and cutthroat trout, and their inland relatives. This would be valid, but would fail to recognize the gradation between Pacific trouts and Pacific salmons. (c) Continue to assign Pacific trout to the genus Salmo, separate from Oncorhynchus. This would be stable, but at the expense of evolutionary information in the classification-rainbow and cutthroat trout are on the same branch of evolution as the Pacific salmon. To reflect these biological relationships in the classification of trouts and salmons will contribute to better understanding of their life histories and better predictions for their management.
\end{abstract}

The AFS Names of Fishes Committee has adopted several changes in North American trout names as outlined in the following article. The American Fisheries Society has implemented use of the new names in all AFS publications produced after January 1, 1989. See also, Fisheries 13(6):24.The Editor.

14 arge quantities of Salmo and hundreds of thousands of tons of Oncorhynchus are caught annually. Many laboratories investigate these fishes, yet there is no agreement on simple and fundamental questions, such as: (1) Does the genus Salmo extend to the Pacific? (2) Does there exist a distinct genus Oncorhynchus distinct from Salmo? Such an uncertainty inevitably renders it impossible to clarify the many obscure questions in regard to the life history of the salmon. If the classification is not clear it is impossible to trace even the distribution of this group. Still less is it possible to elucidate the question of the origin (freshwater or marine) of the salmon; of the biological reason for the inevitable death after spawning of all specimens in some of the species of this tribe; of the origin of the migratory habits of the salmon; of the return of these fish for spawning purposes into their native streams, and many other problems which interest everyone who studies the life history of the salmon.

"Therefore, the first thing that must be done is to attempt to find a natural arrangement of this group."

V. Tchernavin (1937 p. 236)

\section{The Problem}

The internationally accepted ge- neric and specific names of trout and salmon are partly the result of historic sequence of publication of descriptions by early pioneers in fish biology, and partly the result of modifications necessitated by new information on species relationships. At any point in history, people working on classification try to satisfy two criteria: (1) stability of nomenclature and (2) correspondence between classification and knowledge about evolutionary relatedness. These criteria come into conflict when new information compels re-alignment of species groupings. In the present case, information on the relationships of Pacific trouts and salmons has been available for 70 years (since the work of $\mathrm{C}$. Tate Regan in 1914), but people have been reluctant to destabilize names that so many biologists and managers use in their reports and communications. A number of workers have recently decided to correct the classification, but have unfortunately chosen an invalid name, Parasalmo, for classifying $\mathrm{Pa}$ cific trouts. We review the history of trout and salmon names and suggest 
choices which we think will be stable in the future.

The genus Salmo was proposed by Linnaeus in 1758. It originally included the Atlantic salmon and trout (Salmo salar and Salmo trutta, respectively) as well as huchen, chars, grayling, and other soft-rayed fishes. Several decades later, with the exploration of the lands bordering the North Pacific, many new trouts and salmons were discovered. Most of these species (e.g., mykiss, tshawytscha, gorbuscha, nerka, keta, kisutch) were described in Latin by Johann Walbaum (1792) on the basis of specimens collected by Thomas Pennant's expedition in Kamchatka. In 1836, John Richardson described most of them again (e.g., gairdneri, quinnat, scouleri, paucidens, consuetus, tsuppitch) on the basis of specimens from northwestern North America. (Walbaum included the new trouts, salmons, and chars in Linnaeus' genus Salmo. Richardson did the same, except that he separated chars out as the genus Salvelinus.)

Most of the species currently recognized were captured repeatedly by explorers on both sides of the Pacific and were named again by naturalists attempting to describe the spectacular diveristy (e.g., Suckley 1860, 1862). Why were the new discoveries so often thought to represent new species? Partly because they sometimes were, partly because the species concept was less inclusive then, but mostly because the numerous species of trout and salmon show remarkable variation in sexual dimorphism, breeding shapes, colors, and life history.

Walbaum's, Richardson's, and Suckley's names for the same species, above, were mostly sorted out by Jordan and Gilbert (1883). But ichthyologists are still trying to assign properly the other synonyms for our salmonid species and to provide an optimal classification.

\section{Salmo mykiss vs. gairdneri}

Salmo mykiss and Salmo gairdneri have been confused by several cases of mistaken identity. Jordan and Gilbert (1883) used the name irideus for the rainbow trout and gairdneri for the steelhead, and listed "mykiss" as a possible synonym of gairdneri. But
Jordan and Evermann (1896), influenced by characteristics given by Richardson (1836) and Suckley (1860), applied the name mykiss (Walbaum's 1792 Kamchatka trout) to the cutthroat trout, which they mistakenly thought to extend to Kamchatka. In 1898, Jordan and Evermann correctly assigned the name clarki (Richardson 1836) to the cutthroat trout when they discovered that it ranged only to Alaska, not to the Bering Sea, and that mykiss from Kamchatka lack orange on the throat (Jordan and Evermann 1898). But they mistakenly concluded that mykiss was a relative of Salmo salar because their specimen had larger scales (125 lateral series) than the steelhead, gairdneri.

Robert Behnke (1966) corrected the misunderstanding of scale size and provided convincing morphological evidence that the Kamchatka trout and the rainbow trout were similar. Okazaki (1984) added data from 37 electrophoretic loci and demonstrated beyond doubt that coastal steelheads from western North America are genetically more similar to Kamchatka trout (genetic distance $=.0026$ ) than to inland gairdneri (genetic distance $=.0073$ ). Okazaki summarized all of the available evidence, including the identity of vertebral counts (Savvaitova 1975) and chromosome data (Vasil'yev 1975; Thorgard 1977) and concluded that the rainbow trout and the Kamchatka trout are the same biological species, for which the oldest available name is mykiss (which is Walbaum's spelling for an indigenous Kamchatkan name for the rainbow trout).

The facts are solid and the choice seems unambiguous. Although North American biologists could appeal to the International Commission on Zoological Nomenclature to validate the younger name for the species, we think this would be ill advised because mykiss has a well-established place in the Asian literature. It is desirable that we use one formal name to communicate about one species, and the oldest species name of the rainbow trout of Kamchatka and western North America is mykiss. (Recent name changes are explained further by Bailey and Robins 1988.) The American Fisheries Society Committee on Names of Fishes
At the June 1988 meeting of the American Society of Ichthyologists and Herpetologists, the AFS-ASIH Committee on Names of Fishes was able to review thoroughly the study of Pacific trouts outlined by Smith and Stearley in the accompanying article. After examining the evidence, the Committee voted unanimously to accept Oncorhynchus as the proper generic name for these fish, leaving Salmo as the genus of trouts (including the Atlantic salmon) native to Europe, western Asia, and the Atlantic basin. A change in the specific name of rainbow trout from gaindneri to mykiss has been advocated on good evidence by ichthyologists for several years, and the Committee had already accepted it.

The Committee has not endorsed these changes lightly, for it has an overriding interest in the stability of fish names. We consider the evidence supporting the changes too strong to dispute. Only the scientific names are affected; the common names long recommended by the Committee still remain unchanged. The new nomenclature will be reflected in two of the Committee's forthcoming books: "World List of Fishes . . . of Interest to North Americans," scheduled for publication in 1989, and 'List of Common and Scientific Names of Fishes from the United States and Canada," 5th edition, 1990.

\section{Richard Robins, Chair Committee on Names of Fishes}

has established a stable set of vernacular names to assist unambiguous communication while unfamiliar scientific names are put into use.

\section{Oncorhynchus vs. Salmo}

This is a more complicated problem. In 1862, George Suckley proposed Oncorhynchus as a subgenus of Salmo to contain those anadromous species in which the upper jaw of breeding males is "permanently" hooked and in which the teeth become enlarged. He assigned this name to males of Pacific salmon. In a classification written in 1861 and 
published posthumously by the $U$. S. Fish Commission in 1874, Suckley indicated that steelheads belong to a second group of "salmon" (not Oncorhynchus) with females of the species that he placed in Oncorhynchus.

In 1866, Albert Gunther of the British Museum recognized the gender problem in Suckley's classification and redefined Oncorhynchus on the basis of the longer anal fin rather than male breeding characters. Gunther defined Oncorhynchus as having 14 or more anal rays (not knowing that Salmo masou, with 1115 anal fin rays, would be placed in Oncorhynchus). Gunther's account, in his monumental Catalogue of Fishes in the British Museum, formed the basis for much of the modern clas- sification of salmonids. But the generic problem was not clearly solved; for example, D. S. Jordan described the Kamloops rainbow trout as an Oncorhynchus in 1892.

The most important breakthrough in understanding trout relationships occurred in 1914, when C. T. Regan of the British Museum documented evidence that Pacific trouts and salmons formed a natural group, based on shared skull characters, and advocated placing them in the same genus. Regan (1914 p. 407) argued that ". . . the genus Oncorhynchus Suckley can be no longer maintained, unless it be considered that the cranial characters warrant its separation from Salmo; in that case Oncorhynchus will include not only the Pacific Salmon, but the Pacific Trout also." This was the first statement of conclusions since reached by many modern workers. Regan's ideas have survived re-analysis based on a broad diversity of new osteological and biochemical characters. (See Figure 1 for a summary of some of the bone characters supporting the new classification. Our analysis of osteological and other characters is being presented in more technical form elsewhere.)

Regan's intention was clearly that when the characters indicate diverging groups, the generic names should be consistent with those groups. However, later classifications by others (e.g., Jordan et al. 1930) ignored Regan and continued to classify Pacific trouts with Atlantic trouts and salmon in Salmo, on the basis of similarity in the number of anal rays.

Tchernavin $(1937,1938)$ also dis-

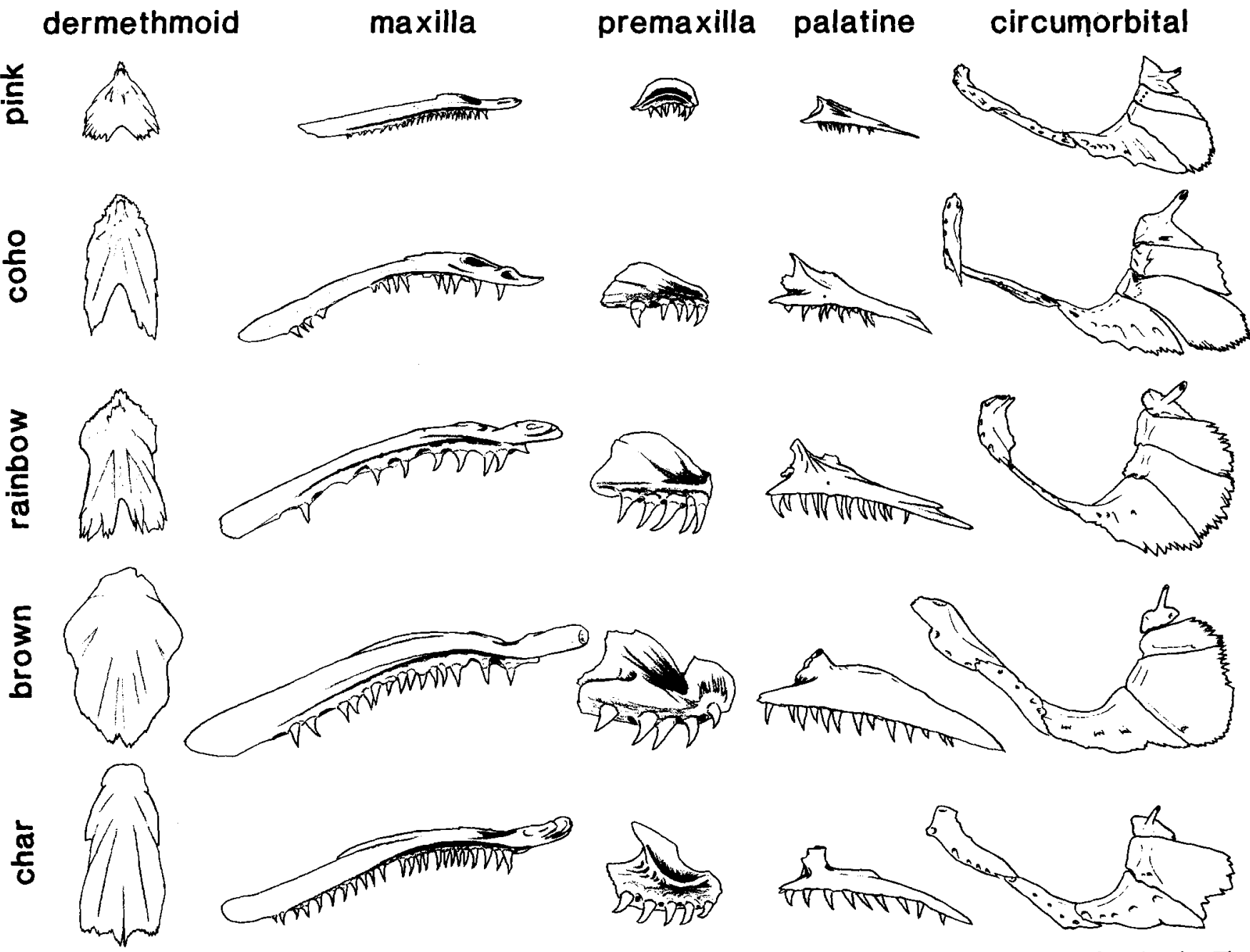

Figure 1. Shapes of five bones shown for Salvelinus confluentus, Salmo trutta, and Oncorhynchus mykiss, kisutch, and gorbuscha. The bones are the dermethmoid (dorsal view), left maxilla (mesial view), left premaxilla (mesial view), left palatine (lateral view), and part of the left circumorbital series (lateral view). The diagrams indicate some of the trends in evolution of groups of salmonid fishes as shown in Figure 2. 
agreed with Regan, concluding that evidence from bones and the chondrocranium supported keeping Pacific trout in the genus Salmo. It is clear that this was because Tchernavin (1937 p. 236) valued primitive characters for defining genera: "Some of these [skeletal] elements seem to retain old ancestral characters and thus afford a guide to the natural arrangement of families and genera; while other elements of the skeleton, mostly those belonging to the investing bones, change with the development of the species and present clear distinctions for determining species." The effect of this criterion on a classification is to emphasize the amount of evolution (similarity), not the branching relationships. (Indeed, the controversy turns on this precise point. A critique of this style of classification was presented by C. L. Smith [1988] in this journal.)

Between Regan's work and the present, the phylogenetic relationships of these fishes have been recognized based on meristics (Rounsefell 1962), osteology (Vladykov 1963; Cavender and Miller 1982; Sanford 1987), biochemistry (Berg and Ferris 1984), and general anatomy (Kendall and Behnke 1984). But the similarity of Pacific trouts to Atlantic trouts, especially in primitive characters (as noted by Tchernavin 1937), permitted workers to be satisfied with the classification. Even though there were two evolutionary lineages, an Atlantic group and a Pacific group, the "trout" in each group were regarded to be at the same "grade" of evolution. Because Pacific "salmons" had evolved beyond that grade, they were thought to require generic status, as Oncorhynchus.

Why should we do it any differently now? C. L. Smith (1988) provided background when he outlined the principles of cladistic classification of fishes. In brief, these are two: First, we discover separate, divergent branches of the evolutionary tree by finding unique anatomical specializations that characterize each group. These specializations, so long as they originated only once in evolution, allow us to identify the members of each group corresponding to a branch of the "tree." Second, in our classification, we apply the formal names to monophyletic groups-those that are restricted to all of the descendants of a common ancestor, i.e., all of the twigs on one branch.
All the species in monophyletic groups are each other's closest relatives. This increases the predictive value of the classification because of correlations between life history and evolutionary relationship.

The alternative, grade classification, leads to generalizations that are based on ancient features that are similar due to lack of change and, therefore, characteristic of rather large, unrelated groups. Although the goal of monophyly is still a debatable practical and philosophical problem in classification (Sokal 1988), many systematists are convinced that the shared specialized characters should have more predictive value and convey more about genealogical relationship than the shared primitive characters (Hennig 1966).

To take the current example, we should compare the kinds of generalizations about morphology, ecology, and life history that are implied by two alternative classifications: (1) The old one-Pacific trout, Atlantic trout, and Atlanitic salmon in Salmo and Pacific salmon in Oncorhynchus, vs. (2) The new one-Atlantic trouts and salmon in Salmo and Pacific trouts and salmons in Oncorhynchus.

The first classification has the advantage of placing together in Salmo most of the species with small anal fins and potential for repeated spawning, apart from the species that have large anal fins and usually die after spawning. It also has the advantage of using the generic name Oncorhynchus to emphasize the extensive amount of evolution that distinguishes most Pacific salmons. The relative lack of divergence of Pacific trouts is acknowledged by classifying them with Salmo, separated from their sister group, the Pacific salmon. In brief, this classification emphasizes the characters that have not changed in evolution, at the expense of characters that have advanced and show kinship.

The second classification separates two groups of species, each of which is diagnosed by possession of uniquely derived morphological traits. The pattern of advancement in these traits indicates two separate evolutionary lineages (see Figure 2): the Atlantic group and the Pacific group. It separates the two branches from each other because of its emphasis on unique morphological specializations and its deemphasis of similarities due to lack of change. It has the disadvantage of combining Pacific salmons with their less evolved sisters, the Pacific trouts, and separating the latter from their ancient and superficially similar sister group, Atlantic trouts and salmons. However, this classification has the advantage of reflecting true historical relationship and evolutionary trends.

The prediction is that the new classification will be more consistent with ecology and life-history, as well as biochemistry and morphology, because aspects of these traits have also been evolving. If selected life history and ecologic traits are mapped onto the phylogeny diagrammed in Fig. 2, their trends can be seen to parallel the history of morphology (Fig. 3). We see that the overall phylogenetic history of the Salmoninae supports a stepwise transition from freshwater forms (like Thymallus and Brachymystax) to levels of intermediate anadromy (as in Salvelinus) to increasing loss of dependence on freshwater stages in Oncorhynchus (Tchernavin 1939). This, however, does not rule out the possibility of isolated trends in the other direction. For example, the inland forms of the rainbow trout and the sockeye salmon could be derived from the anadromous forms, as suggested by Thorpe 1982, rather than the other direction. The osmoregulatory ability to deal with sea life is almost certainly a primitive trait for the Salmonidae, since it is found in other closely related families, such as the Osmeridae.

The phylogeny suggests that there should be a continuity (with occasional reversals) of development of life history traits along the branch of Pacific trouts and salmons. This is, in fact, what we see. Pacific salmons grade toward their distinctive life history from Pacific trouts in small steps. Most steelheads die after spawning and some salmon actually have individuals that repeat as spawners. The mechanism of death appears to be highly similar in steelhead and in Pacific salmon (Robertson and Wexler 1962a,b), involving rapid senescence due to accelerated pituitary and adrenal activity. But Oncorhynchus masou, of Japan, has populations that always die after spawning and other populations (sometimes called Oncorhynchus rhodurus, see Masuda et al. 1984) that do not (see also Jordan and Evermann 1896).

Further trends in life history traits 
occur within the Pacific salmons. Oncorhynchus tshawytscha and nerka both exhibit an unusual "experiment" in life history: a small percent of fry go directly to sea (Scott and Crossman 1973). The sea-going fry of $O$. nerka are presumed not to survive. Oncorhynchus keta and gorbuscha reduce the freshwater phase of life to a minimum, emerging from the gravel ready to migrate. These trends are used by Hikita (1962) and Hoar $(1958,1976)$ to demonstrate that the subgroup, nerka, keta, gorbuscha, is more derived than other Oncorhynchus.

In summary, we see that Pacific trouts are a middle part of a trend that is continued by their close relatives, the Pacific salmons. When viewed this way, we may see more continuities in their ecology and life history, although variations and reversals in trends are certainly a part of the evolution of the group.

\section{Parasalmo and Rhabdofario}

Recently, ichthyologists have expressed an interest in using the subgeneric name Parasalmo Vladykov 1963 as a generic name to emphasize the difference between Pacific and Atlantic trout (Kendall and Behnke 1984; Berg and Ferris 1984; Berg and Gall 1988). This would have the advantage of emphasizing the evolutionary divergence of the Pacific group from the Atlantic group and Pacific salmons from Pacific trouts. Although attractive on the surface, we see two reasons against using the name Parasalmo as a solution to the problem.

First, should we wish to emphasize their distinctiveness, there are two generic names available for the Pacific trouts: Rhabdofario (Cope 1870) and Parasalmo (Vladykov 1963). The older name has not received as much attention because it is based on part of a fossil skull (Fig. 4) from the Pliocene Glenns Ferry Formation of Idaho. Our studies of Rhabdofario, based on a number of excellent fossil skull and jaw bones, has convinced us that it represents the same evolutionary lineage as rainbow and cutthroat trouts. The name Parasalmo applies to the same group (as Vladykov 1963, recognized) so if Pacific trouts are to be recognized with a separate generic (or subgeneric) name, the older one, Rhabdofario, is the required choice, under the rules of nomencla-

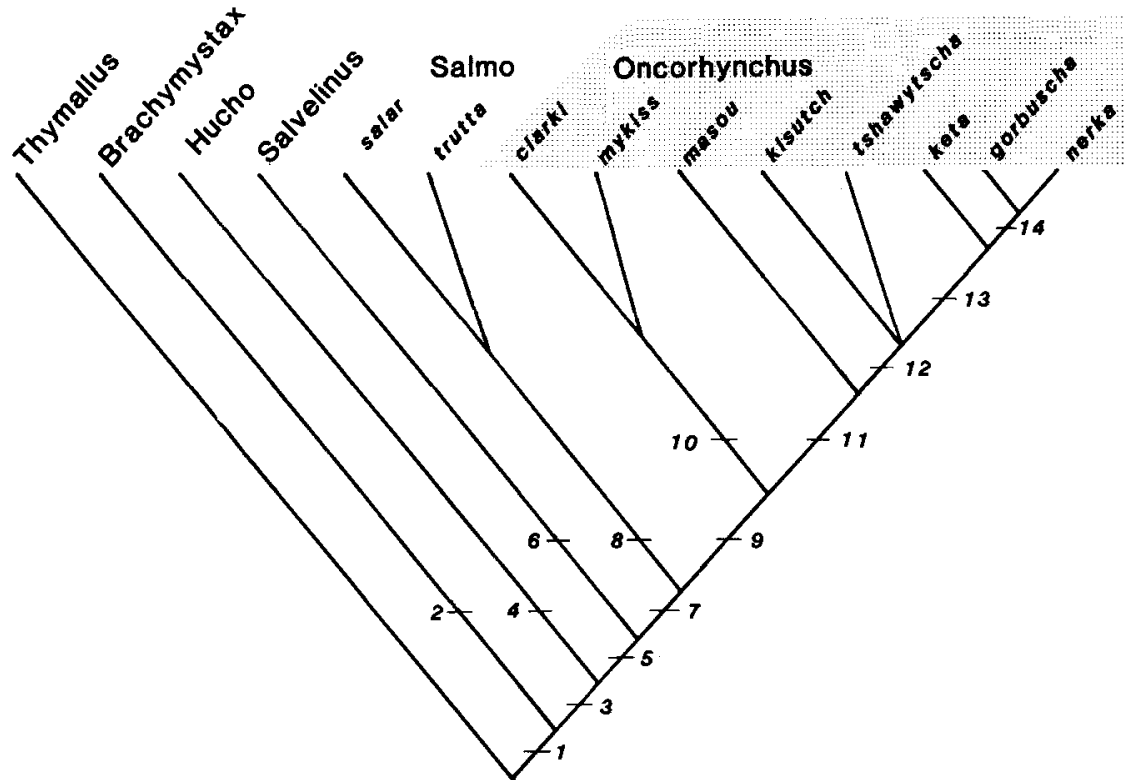

Figure 2. Phylogenetic tree of relationships of genera of salmonid fishes, summarized from an analysis of $\mathbf{4 9}$ morphological characters and 24 species (see box for key to some of the characters). The tree was calculated with David Swofford's program, "Phylogenetic Analysis Using Parsimony." The program finds the shortest tree, assuming that the characters originated uniquely and reverse rarely. Although these assumptions need not be true for each character, the method produces reliable results if they are generally true over the entire tree. The above tree is consistent with many published molecular data sets. See Figure 3 for common names.

The following characters provide evidence for the branches in the evolutionary tree in Figure 2. These are chosen from among 49 morphological characters that were used to calculate the tree (Stearley and Smith, in preparation). The characters at each number are specializations shared by the species above the stem next to the number.

1. Parietals separated, small extrascapulars, suprapreopercular present, maxilla with anteroventral corner and large premaxillary process, fan shaped stegural.

2. Long supraethmoid.

3. Maxilla long, head broad anteriorly (Fig. 1), gill rakers robust, kype in large breeding males.

4. 11-16 gill rakers, parasphenoid flat posteriorly.

5. Reduced lower limb of preopercle, dermethmoid broader posteriorly (Fig. 1).

6. Teeth on elevated vomerine crest, 5 infra- and post orbitals (Fig. 1), wide second infraorbital (Fig. 1), nonossified orbitosphenoid septum.

7. Ovate supramaxilla, vomer extending posterior to lateral ethmoid, anterior extension of vomer in breeding males, sphenotic laterally rotated, teeth on shaft of vomer.

8. Narrow subopercle, premaxilla with large process medial to ethmoid pocket (Fig. 1).

9. Short palatine crest (Fig. 1), broad posterior notch in supraethmoid (Fig. 1), intercalar contacts pro-otic, posterior parasphenoid U-shaped in cross-section, medium-long post-orbitals (Fig. 1).

10. Robust anterior dentary (Fig. 4), parr-marks in dorsal midline, black spots on adipose margin.

11. Long postorbitals (Fig. 1), short ceratohyal, vomerine-palatine tooth gap, ethmoid cartilage azygous in adults.

12. Thirteen or more anal rays, temporal fontanelle absent in adults.

13. Straight maxilla (Fig. 1), anterior constriction of supraethmoid, slender tapered glossohyal, thin crest on premaxilla (Fig. 1), smaller adult size.

14. Gill rakers more than 26 , small teeth on maxilla (Fig. 1) and posterior dentary, pronounced hump in breeding males.

Characters for Figure 3

1. Egg diameter larger than $4.5 \mathrm{~mm}$; dig redds; kype in large breeding males (Berg 1948; Holcik 1982; Morton 1965; Sterba 1963).

2. Fall spawning season (Berg 1948; Scott and Crossman 1973).

3. Capable of long migrations at sea.

4. Often irreversible hormonal changes in post-spawning migratory forms (Robertson and Wexler 1962a, b).

5. Spring spawning season.

6. All anadromous forms die post-spawning.

7. Stream-resident residuals do not reproduce.

8. Most smolt at age $0+$; some go to sea as fry (Scott and Crossman 1973)

9. Strong schooling behavior of juveniles and slender parr (Hikita 1962; Hoar 1958, 1976).

10. Reduced freshwater phase; emerge from gravel ready to migrate (Hoar 1976). 
ture. There is nothing wrong with the use of a valid name originally based on an extinct trout, but we think there is a second problem to be considered.
The pattern of the gradation between trouts and salmons argues against separation of Pacific trouts as a separate genus. The distribution of morpho-

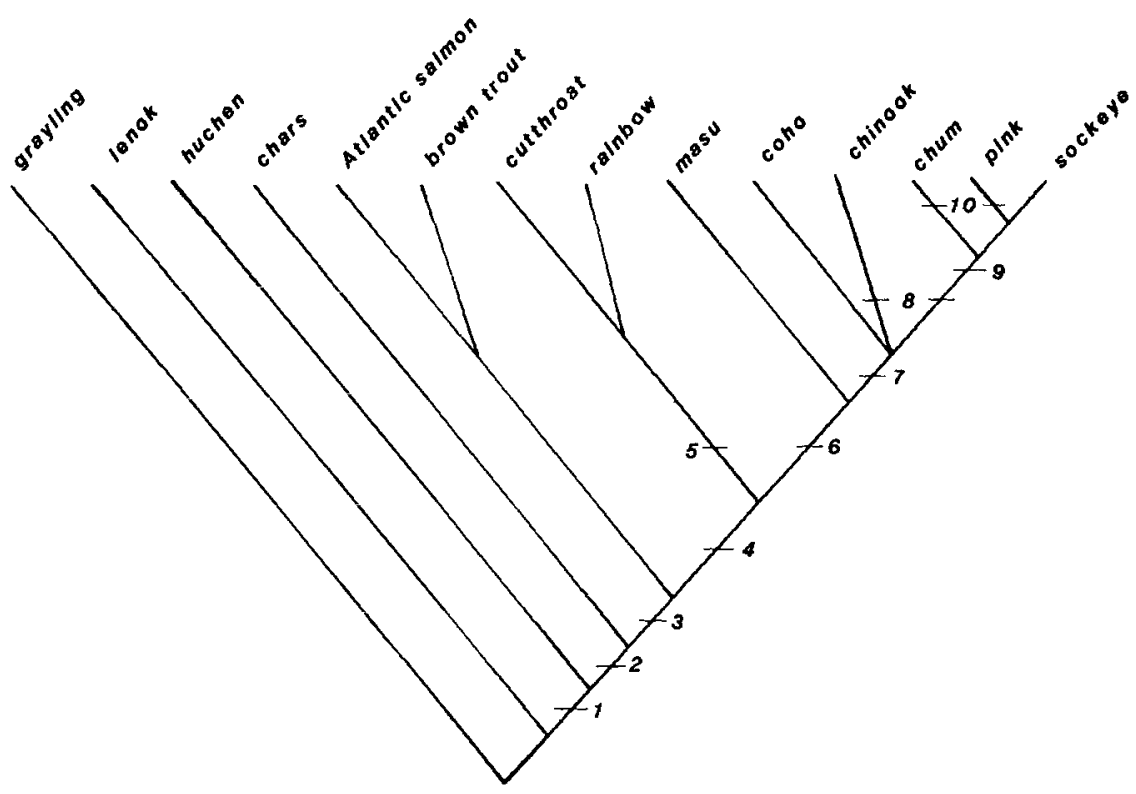

Figure 3. Some selected life history traits mapped on the phylogenetic tree in Figure 2 to demonstrate possible transition points and trends in evolution of life history in salmonids. Note that the tree is not constructed from the life history data, but these data are merely plotted on the phylogeny derived from morphological characters. Each life history trait is mapped onto the tree as though it evolved only once. However, it is likely that many life history traits frequently evolved in parallel or reversed direction. For example, see character 13; emergence from the gravel ready to migrate is required to evolve twice if the tree in Figure 2 is true. Pink and sockeye salmon have similar schooling responses (Hoar 1976), supporting the tree. But if chum and pink salmon are sister groups (as indicated by some mtDNA data [Thomas et al. 1986]), origin of character 10 could be shown as a single event. The exercise shown in this figure is preliminary; more life history data need to be compiled.

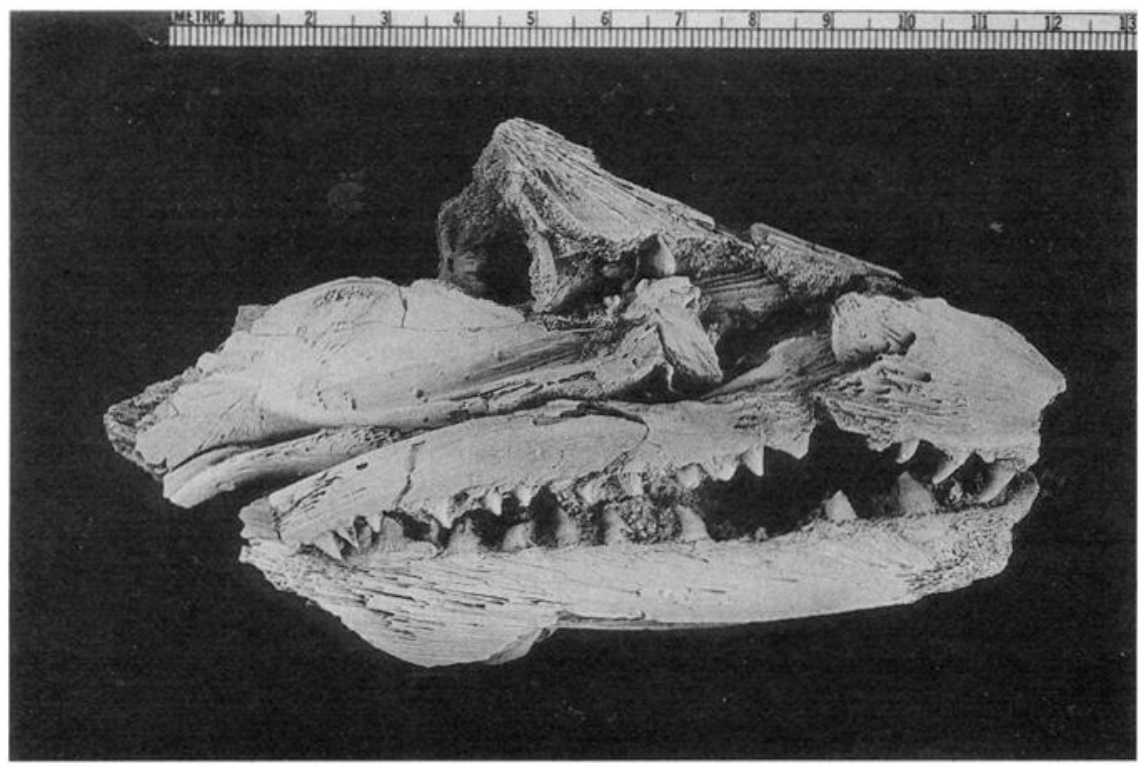

Figure 4. Partial skull from a trout that lived 3.5 million years ago in the Snake River drainage of Idaho, showing characteristic maxilla and premaxilla of rainbow and cutthroat trout. On the basis of this fossil skull, the trout was named Rhabdofario lacustris by the great naturalist, E. D. Cope, in 1870. (From Smith 1975.) logical, biochemical, and ecological character states shows a primitive group, trouts, whose anadromous forms are salmon-like, and an advanced group, salmon, the earliest members of which are trout-like (Fig. 2). Oncorhynchus masou, for example, is intermediate between trout and salmon in osteology, biochemistry, and life history. The choice of a generic division would have to be arbitrary with respect to the landlocked forms of masou, which are repeat spawners, and the sea-run forms, which die after spawning. Clearly, two forms of the same species cannot be in different genera. If the choice is that arbitrary, the arguments favoring it are difficult to support.

\section{Recommendation}

For the reasons outlined above we favor restricting the name Salmo to Atlantic salmon, brown trout, and their Eurasian relatives, e.g., the trouts in Lake Ohrid and Lake Sevan. Two species of Salmo are anadromous, but both of these have landlocked forms: Salmo salar has inland forms in North America and Salmo trutta has inland forms in Eurasia and Morocco. The number of species that should be recognized in this group is not certain, but they display significant diversity in morphology, life history, and spawning seasons. For example, Salmo ischchan of Lake Sevan in the Soviet Union has six forms, including fall, spring, and summer spawners (Berg 1948). Despite this diversity, it has not seemed necessary to recognize Atlantic trout and salmon in different genera.

The complementary sister genus in the north Pacific basin is Oncorhynchus, which includes eight sea-run species, four of which have inland, land-locked relatives. In Japan, the Amago and Biwa trout represent $O$. masou. Similarly, the North American kokanee represents $O$. nerka, and the inland rainbow, cutthroat, golden, Mexican golden, Apache, and Gila trout, are related to anadromous $O$. mykiss and O. clarki. The exact species limits of the inland forms of both Salmo and Oncorhynchus present us with one of the current challenges in the biology and management of trouts. We think that the above classification will contribute a framework that will help researchers understand and manage this diverse and biologically complex resource, be- 
cause this classification is more consistent with the growing body of biochemical and life-history information about these fishes.

\section{Acknowledgments}

We are grateful to R. M. Bailey, W. L. Fink, W. A. Gosline, R. R. Miller, D. Nelson, and P. Seelbach, for reading the manuscript and making suggestions. C. Bond provided specimens and helpful suggestions. R. Robins and D. Begle provided useful discussions.)

\section{References}

Bailey, R. M., and C. R. Robins. 1988. Changes in North American fish names, especially as related to the International Code of Zoological Nomenclature, 1985. Bull. Zool. Nomencl. 45(2):92-103.

Behnke, R. 1966. Relationships of the far eastern trout, Salmo mykiss Walbaum. Copeia 1966:346-348.

Berg, L. 1948. Freshwater fishes of the U.S.S.R. and adjacent countries. Vol 1. Acad. Sci. U.S.S.R., Moscow. 493 pp.

Berg, W. J., and S. D. Ferris. 1984. Restriction endonuclease analysis of salmonid mitochondrial DNA. Can. J. Fish. Aquat. Sci. 41:1041-1047.

Berg, W. J., and G. A. E. Gall. 1988. Gene flow and genetic differentiation among California coastal rainbow trout populations. Can. J. Fish. Aquat. Sci. 45:122131.

Cavender, T. M., and R. R. Miller. 1982. Salmo australis, a new species of fossil salmonid from southwestern Mexico. Contrib. Mus. Paleontol. Univ. Mich. 26:1-17.

Cope, A. D. 1870. On the fishes of a freshwater Tertiary in Idaho, discovered by Capt. Clarence King. Proc. Am. Philos. Soc. 11:538-547.

Gunther, A. 1866. Catalogue of fishes in the collection of the British Museum, Vol. 6. $368 \mathrm{pp}$.

Hennig, W. 1966. Phylogenetic systematics. University of Illinois Press, Urbana. 263 pp.

Hikita, T. 1962 . Ecological and morphological studies of the genus Oncorhynchus (Salmonidae) with particular consideration on phylogeny. Sci. Rep. Hokkaido Salmon Hatchery, No. 17. 97 pp.

Hoar, W. S. 1958. The evolution of migratory behaviour among juvenile salmon of the genus Oncorhynchus. J. Fish. Res. Board Can. 15:391-428.

- 1976. Smolt transformation: evolution, behavior, physiology. J. Fish. Res. Board Can. 33:1234-1252.

Holcik, J. 1982. Review and evolution of Hucho (Salmonidae). Acta. Sci. Nat. Acad. Sci. Bohemoslov Brno 16(3):1-29.
Jordan, D. S., and B. W. Evermann. 1896. The fishes of North and Middle America. US Natl. Mus. Bull. 47 (1): 1-1240. 1898. The fishes of North and Middle America. US Natl. Mus. Bull. 47(3): 21833136.

Jordan, D. S., B. W. Evermann, and H. W. Clark. 1930. Checklist of the fishes of North and Middle America. Report of the U.S. Commissioner of Fisheries for 1928 , appendix $X .670 \mathrm{pp}$.

Jordan, D. S., and C. H. Gilbert. 1883. A synopsis of the fishes of North America. US Natl. Mus. Bull. 16:1-1018.

Kendall, A. W., Jr., and R. J. Behnke. 1984. Salmonidae: development and relationships. Pages 142-149 in H. G. Moser, ed. Ontogeny and systematics of fishes. American Society of Ichthyologists and Herpetologists Special Publication 1.

Linnaeus, C. 1758 . Systema naturae. Facsimile of Tenth Edition. British Museum (Natural History), 1939

Masuda, H., K. Amaoka, C. Araga, T. Uyeno, and T. Yoshino. 1984. The fishes of the Japanese archipelago. Vol. 1. Tokai University Press, Tokyo. $437 \mathrm{pp}$.

Morton, W. M. 1965. The taxonomic significance of the kype in American salmonids. Copeia 1965:14-19.

Okazaki, T. 1984. Genetic divergence and its zoogeographic implications in closely related species Salmo gairdneri and Salmo mykiss. Japanese J. Ichthyol. 31(3):297311.

Regan, C. T. 1914. The systematic arrangement of the fishes of the family Salmonidae. Ann. Mag. Nat. Hist. Vol. XIII (Eighth Series):405 408.

Richardson, J. 1836. Fauna Boreali-Americana. Part III, The Fish. London and Norwich.

Robertson, O. H., and B. C. Wexler. 1962a. Histological changes in the pituitary gland of the rainbow trout (Salmo gairdneri) accompanying sexual maturation and spawning. J. Morphol. 110:157-169.

1962b. Histological changes in the pituitary gland of the Pacific salmon (genus Oncorhynchus) accompanying sexual maturation and spawning. J. Morphol. 110:171-185.

Rounsefell, G. A. 1962. Relationships among North American salmonidae. US Fish Wildl. Serv. Fish. Bull. No. 131, 58:171185.

Sanford, C. P. J. 1987. Salmonid inter- and intrarelationships. Page 78 in American Society of Ichthyologists and Herpetologists, Program and Abstracts.

Savvaitova, K. A. 1975. The population structure of Salmo mykiss in Kamchatka. J. Ichthyol. 15(6):876-888.

Scott, W. B., and E. J. Crossman. 1973. Freshwater fishes of Canada. Bull. 184 Fish. Res. Board Can. 966 pp.

Smith, C. L. 1988. Minnows first, then trout.
Fisheries (Bethesda) 13(4):4-8.

Smith, G. R. 1975. Fishes on the Pliocene Glenns Ferry Formation, Southwest Idaho. Univ. Michigan Papers on Paleontology 14:1-68.

Sokal, R. R. 1988. Unsolved problems in numerical taxonomy. Pages 45-56 in $\mathrm{H}$. H. Bock, ed. Classification and related methods of data analysis. Elsevier Science Publishers B. V., Amsterdam, Netherlands.

Sterba, G. 1963. Freshwater fishes of the world. The Viking Press, New York. 878 pp.

Suckley, G. 1860. Report upon the fishes collected on the survey (1) Report upon the Salmonidae. In Reports of explorations and surveys to ascertain the most practical and economical route for a railroad from the Mississippi River to the Pacific Ocean. Vol. xii, book 2, Zoological Report no. 5:307-349.

_ــ. 1861 (1862). Notices of certain new species of North American Salmonidae from the north-west coast of America. Annals of the Lyceum of Natural History 7:306-313.

- 1874. On the North American species of salmon and trout. Report of the Commissioner for 1872-73, Part 2, pp. 91-160.

Tchernavin, V. 1937. Skulls of salmon and trout. Salmon Trout Mag. 88:235-242.

1938. Notes on the chondocranium and branchial skeleton of Salmo. Proc. Zool. Soc. Lond. Vol. 108 (Series B):347364.

1939. The origin of salmon. Salmon Trout Mag. 95:120-140.

Thomas, W. K., R. E. Withler, and A. T. Beckenbach. 1986. Mitochondrial DNA analysis of Pacific salmonid evolution. Can. J. Zool. 64:1058-1064.

Thorgaard, G. H. 1977. Chromosome rearrangements and sex chromosomes in the rainbow trout and sockeye salmon. $\mathrm{Ph}$. D. thesis, University of Washington, Seattle. vii +102 pp.

Thorpe, J. E. 1982. Migration in salmonids, with special reference to juvenile movements in freshwater. Pages 86-97 in E. L. Brannon and E. O. Salo, eds. Proceedings of the salmon and trout migratory behavior symposium. University of Washington, Seattle.

Vasilyev, V. P. 1975. Karyotypes of different forms of the Kamchatka trout, Salmo mykiss and the rainbow trout, Salmo gairdneri. J. Ichthyol. 15(6):889-900.

Vladykov, V. 1963: A review of salmonid genera and their broad geographical distribution. Trans. R. Soc. Can. Series 4, Vol. 1, Section 3:459-504.

Walbaum, J. J. 1792. Petri Artedi renovati, i.e., bibliotheca et philosophia ichthyologica. Ichthyologiae pars III. Grywewaldiae. A. F. Roese. 723 pp. 